\title{
ROLE OF MINI PCNL IN THE TREATMENT OF RENAL AND UPPER URETERIC CALCULUS
}

\author{
N. Rama Murthy'1, J. Sasi Kumar², P. Rahul Tej33, B. Srinivas' ${ }^{4}$ B. Swapnil5, Y. Anil Reddy 6
}

1Associate Professor, Department of Urology, Mamata Medical College, Khammam, Telangana, India.

2Professor, Department of Urology, Mamata Medical College, Khammam, Telangana, India.

$32^{\text {nd }}$ Year Postgraduate Student, Department of Urology, Mamata Medical College, Khammam, Telangana, India.

${ }_{4}^{4}$ nd Year Postgraduate Student, Department of Urology, Mamata Medical College, Khammam, Telangana, India.

51st Year Postgraduate Student, Department of Urology, Mamata Medical College, Khammam, Telangana, India.

${ }^{6} 1^{\text {st }}$ Year Postgraduate Student, Department of Urology, Mamata Medical College, Khammam, Telangana, India.

\section{ABSTRACT}

\section{BACKGROUND}

In this article we describe our institutional experience with mini PCNL, in particular the indications, results and the complications of this method.

\section{MATERIALS AND METHODS}

It is a prospective observational study. We prospectively reviewed the outcomes of 54 patients who underwent mini-PCNL in our institute from January 2018 to November 2018. Mean age was 47.2 years and mean stone size was 18.4 mm. Hydronephrosis and/or hydroureterosis appeared in all patients. In the prone position, percutaneous access (18-Fr Amplatz sheath) was established by placement of an access needle into the intended calyx under fluoroscopic guidance with single step dilatation. Pneumatic lithotripter was used for fragmentation. The ureteral stents and nephrostomy tube were placed at the end of the procedure in all patients. Mean drop in haemoglobin, transfusion rate, operative time, success rate, hospital stay, and complications were assessed.

\section{RESULTS}

Mini-PCNL operations were performed successfully in all patients. Mean operation time was 48.4 min. Mean postoperative hospital stay was 54 hours. No major complications like haemorrhage, perforation or organ injury was noted during the operation or postoperatively. The stone-free rate in upper ureteric calculi was $100 \%$ and for renal calculi it was $93.1 \%$ and for both it was $100 \%$. Hydronephrosis and hydroureterosis disappeared or were relieved and mean haemoglobin drop was $0.8 \%$.

\section{CONCLUSION}

Mini-PCNL is a safe and effective therapy for proximal ureteral stones and renal calculi up to $2 \mathrm{cms}$ and multiple calyceal calculi.

\section{KEY WORDS}

Mini PCNL, PCNL, Upper Ureteric Calculus, Renal Calculus.

HOW TO CITE THIS ARTICLE: Murthy NR, Kumar JS, Tej PR, et al. Role of mini PCNL in the treatment of renal and upper ureteric calculus. J. Evolution Med. Dent. Sci. 2019;8(03):170-173, DOI: 10.14260/jemds/2019/37

\section{BACKGROUND}

PCNL is a well-established treatment option for patients with large and complex renal calculi. The overall complication rate of PCNL can be up to $83 \%$, which can be minimised by accurate patient selection and careful postoperative followup 1 . PCNL underwent relentless evolution over the years, aimed at reducing its invasiveness and complication rates and improving outcomes.2,3,4,5,6,7 Despite these advances, PCNL remains a challenging procedure with associated morbidity. Postoperative sepsis (2\%), fever (10-16\%), blood transfusion (3-6\%), significant bleeding (8\%), and perforation of adjacent organs (0.4\%) are still important complications after PCNL.8,9

'Financial or Other Competing Interest': None.

Submission 12-12-2018, Peer Review 08-01-2019,

Acceptance 14-01-2019, Published 21-01-2019.

Corresponding Author:

Dr. J. Sasi Kumar,

Professor,

Department of Urology,

Mamata Medical College,

Khammam,

Telangana, India.

E-mail: jonnalagaddasasikumar@gmail.com

DOI: $10.14260 /$ jemds $/ 2019 / 37$

\section{(c) (i) $(9)$}

In order to decrease morbidity associated with larger instruments like blood loss, postoperative pain and potential renal damage, a modification of the technique of standard PCNL has been developed by using a miniature endoscope via a small percutaneous tract (11-20 F) and was named as minimally invasive or mini-PCNL. This method was initially described as an alternative percutaneous approach to large renal stones in a paediatric patient population. Furthermore, it has become a treatment option for adults as well, and it is used as a treatment for calculi of various sizes and locations. The most important difference between the various PCNL techniques is the size of the renal access which contributes to broad spectrum of complications and outcomes.

So, to evaluate the efficacy and safety of mini-PCNL in proximal ureteral calculi and renal calculus we started this hospital-based study (January 2018- November 2018) to use mini-PCNL (15F semi-rigid nephroscope via a 18-Fr percutaneous tract) for the treatment of proximal ureteral calculi (from PUJ to lower border of L4 vertebra) and renal calculi of $\leq 20 \mathrm{~mm}$.

\section{MATERIALS AND METHODS}

After obtaining the ethical clearance, this prospective observational study was conducted in the Department of Urology, Mamata Medical College, Khammam Uanuary 2018 
to November 2018). The study comprised of 54 patients with upper ureteric calculus and renal calculus of size less than 20 $\mathrm{mm}$. All cases were diagnosed using NCCT-KUB

\section{Inclusion Criteria}

1. Stones located between the pelviureteric junction and the upper border of the 4th lumbar vertebra.

2. Renal stone $<20 \mathrm{~mm}$ in largest diameter by NCCT-KUB.

\section{Exclusion Criteria}

1. Coagulopathy.

2. Pyonephrosis.

Preoperatively, patients were evaluated by a urine routine test, urine culture and sensitivity test, plain radiography of kidneys, ureters and bladder (KUB), and intravenous urography.

Ultrasonography or unenhanced helical computed tomography for the degree of hydronephrosis.

Antibiotics were administered prophylactically to all patients with WBC-positive urine. Calculus clearance was assessed on postoperative day 1 with a plain film of KUB. 'Stone-free' was defined as no residual stones or fragments $\leq$ $3 \mathrm{~mm}$ detected on $\mathrm{KUB}$, as fragments $\leq 3 \mathrm{~mm}$ have a likelihood of passing spontaneously. The operative time was calculated from performing the puncture to placing of the nephrostomy, which is also called skin-to-skin time. The time from insertion of the ureteric catheter to the turn in the prone position was not included. Drop in haemoglobin was calculated by comparing preoperative haemoglobin to postoperative haemoglobin on POD2. Pain scale was accessed using visual analogue scale. Transfusion rate was accessed basing on number of transfusions required and hospital stay was accessed from day of surgery to discharge date.

\section{Operative Technique of Mini-Percutaneous Nephrolithotripsy (Mini-PCNL).}

Under general anaesthesia, patient was placed in dorsal lithotomy position. Cystoscopically, the retrograde ureteric catheterization $(4 \mathrm{~F})$ is done and position confirmed under fluoroscopy. This ureteric catheter is used to perform realtime fluoroscopic contrast and/or air pyelography; which helps in making the puncture accurately into the intended calyx. After confirming the position of ureteric catheter, the indwelling catheterization is done, and both the ureteric catheter and ID catheter are tied and secured over posterolateral aspect of opposite thigh. The patient is now positioned in "Swimmer's" prone position and the $\mathrm{C}$-arm adjusted and fixed. In prone position, the puncture is made by using a $16 \mathrm{~cm}$ long (18G) puncture needle by Triangulation technique. In patients where ureteric catheter could not be negotiated, blind puncture of the pelvis is done at renal angle. The position of the needle is confirmed, in the pelvicalyceal system, by observing free flow of normal saline through the puncture needle injected from below. After the successful puncture is made, a 0.035 " Turemo guide-wire is introduced into the pelvicalyceal system and if possible, into the corresponding ureter and thus urinary bladder. The puncture needle is removed, and the tract is dilated over a 0.035" hydrophilic Turemo guide-wire using a $16 \mathrm{~F}$ fascial screw dilator and further dilated to $18 \mathrm{~F}$ and Amplatz sheath is then introduced through the dilated tract into the PCS under C- arm guidance. The $15 \mathrm{~F}$ semirigid nephroscope is introduce and the stone (s) visualized. The stones, once identified are fragmented using a Lithoclast for lithotripsy, most stone fragments $(<4 \mathrm{~mm})$ could be flushed out, by infusion of normal saline irrigation, along with the backflow through the Amplatz sheath, while the remaining big fragments are extracted with stone forceps. Once complete intra-operative, i.e. nephroscopic and C-arm clearance is achieved, a 5F DJ stent is then placed in. $8 \mathrm{~F}$ feeding tube is placed as nephrostomy tube in all patients. X-ray KUB is done on POD1 to look for DJ stent position and residual stone fragments, if visualized.

\section{Follow-Up}

Patients with residual fragments on POD1 have underwent relook mini PCNL and cleared of remaining fragments and inaccessible fragments were subjected to ESWL at a later date. The patient was deemed stone free when there was complete clearance of all stone fragments or the presence of fragments $<3 \mathrm{~mm}$, seen on NCCT KUB after all interventions. The procedure was defined as unsuccessful when the procedure was converted into some alternative treatment modality, or the stone could not be reached or fragmented.

\section{Statistical Analysis}

The recorded data was compiled and entered in a spreadsheet (Microsoft Excel) and then exported to data editor of SPSS Version 20.0 (SPSS Inc., Chicago, Illinois, USA). Continuous variables were summarized in the form of means and standard deviations and categorical variables were summarized as percentages.

\section{RESULTS}

Of 54 patients 18 had only upper ureteric calculus, 7 had upper ureteric and renal calculus and 29 had renal calculus. All patients with upper ureteric calculus achieved 100\% clearance with single puncture. Of the 7 patients with both upper ureteric calculus and renal calculus 6 achieved 100\% clearance with single puncture in first attempt, one required second puncture on POD 4 for migrated calculus into middle calyx which was missed initially. Of 29 patients with renal calculi 25 patients achieved $100 \%$ clearance with single puncture in first attempt, 2 required re look mini PCNL on POD3 and achieved 100\% clearance subsequently and 2 patients were subjected to ESWL due to calculi migration to superior calyx and failed subsequently giving an overall success rate of $93.1 \%$. Demographically, the mean age of patients was $41.5 \pm 6.31$ years and range of $26-54$, male to female ratio was $31: 23$, the disease laterality (Right: Left) was $35: 19$ and mean stone size was $18.4 \pm 2.06 \mathrm{~mm}$ (Table 1 ). None of the patients had previous history of ESWL. The mean operative time was $48.4 \pm 3.02$ minutes. The mean hospital stay $54 \pm 6.08$ hours. At discharge from the hospital, stone free rates were $96.2 \% .52 / 54$ (Table 2). In our study, the overall complication rate was $7.4 \%$; with 2 patients $(3.7 \%)$ developing post-operative fever and 2 patients $(3.7 \%)$ had prolonged hematuria and both underwent second procedure, of these no patients with upper ureteric calculus had any complications. No patient had required any blood transfusion in the post-operative period and mean haemoglobin drop was $0.8 \%$. The mean analgesia requirement (In the form of injectable tramadol) was found to be $50 \pm 16.45 \mathrm{mg}$ (Table 2) 
and all patients were withdrawn analgesia at discharge. No loss of follow-up was noted.
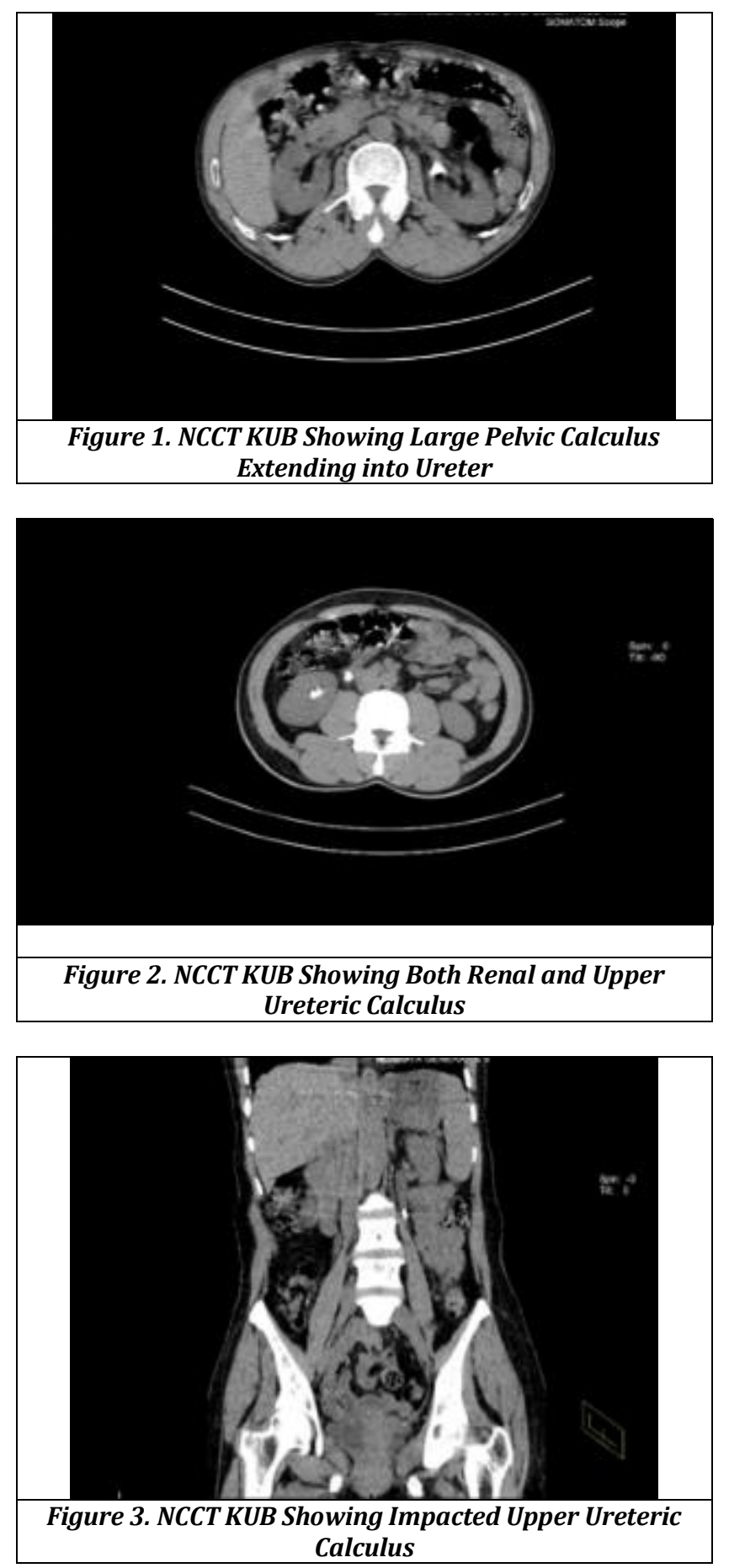

\begin{tabular}{|c|c|}
\hline Mean age (yrs.) (Range) & $\mathbf{4 1 . 5} \pm \mathbf{6 . 3 1}$ \\
\hline Male to Female Ratio & $31: 23$ \\
\hline Disease Laterality (R/L Ratio) & $35: 19$ \\
\hline Mean Stone Size (mm) & $18.4 \pm 2.06 \mathrm{~mm}$ \\
\hline \multicolumn{2}{|c|}{ Table 1. Demographic Characteristics } \\
\hline
\end{tabular}

\begin{tabular}{|c|c|}
\hline Variables & Results \\
\hline Mean Operative Time (Mins.) & $48.4 \pm 3.02$ \\
\hline Mean Hospital Stay (Hours) & $54 \pm 6.08$ \\
\hline Mean Haemoglobin Drop & $0.8 \%$ \\
\hline Stone Free Rate on Discharge & $96.2 \%$ \\
\hline Overall Complication Rate & $7.4 \%$ \\
\hline
\end{tabular}

\begin{tabular}{|c|c|}
\hline $\begin{array}{c}\text { 1. Fever } \\
\text { 2. Prolonged Haematuria } \\
\text { 3. Stone Migration } \\
\text { 4. Thoracic Complications }\end{array}$ & $\begin{array}{l}1.3 .7 \% \\
2.3 .7 \% \\
3.7 .4 \% \\
4 . \text { nil }\end{array}$ \\
\hline Ureteral Injury & Nil \\
\hline Analgesia Requirement (mg) & $50 \pm 16.45 \mathrm{mg}$ \\
\hline Transfusion Rate & Nil \\
\hline
\end{tabular}

\section{DISCUSSION}

Renal and Ureteric calculi is a common entity encountered in urology clinics. With increasing size and duration these calculi pose a serious threat to the function of the kidney on the affected side and, thus, the health of the patient. Therefore, timely effective treatment is the key to prevent irreversible damage.

Technical achievements have revolutionized the methodology for the removal of renal and ureteral stones. Open procedures were, once used to be the standard treatment, however, with the advent of lithotriptors, endourology and laparoscopy, less invasive procedures are preferred. Although traditional PCNL has many advantages, such as clear vision, high stone clearance rate and short operation time, the indications were strictly limited for a number of serious complications. ${ }^{10}$

In our study, a significantly longer mean operative time was seen in retrieving renal calculi which is about $68 \mathrm{~min}$ whereas the operative time for ureteric calculi is significantly shorter 36 min (Table 2) which is comparable with several studies, (155.5 min and $45 \mathrm{~min}$ vs. $106.6 \mathrm{~min}$ and $31 \mathrm{~min}$ respectively). ${ }^{11,12}$ In our study, the mean hospital stay was significantly shorter $54 \pm 6.08$. (Table 2 ).

In our study, at discharge from the hospital, stone free rates was $96.2 \%$. A significantly higher success rate $(96.2 \%)$ was noted in our study. We had $100 \%$ clearance for ureteric stones and $93.1 \%$ for renal calculi where as $85.7 \%$ clearance in patients at first puncture and achieved $100 \%$ clearance with relook mini PCNL. Similar comparisons were observed in various previous studies. ${ }^{13,14,15}$

Fever and hematuria are known complications of the procedure.16,17,18 In our study, two patients each developed post-operative fever and prolonged hematuria $3.7 \%$ respectively). No patient required blood transfusion and mean haemoglobin drop observed was very minimal $0.8 \%$.

The mean analgesic requirement (In the form of injectable tramadol) was found to be on lower side (50 \pm $16.45 \mathrm{mg}$ ), which signifies that the post-operative pain is significantly less. For all patients, analgesia was stopped at the time of discharge.

In our study, the stone/fragment (s) migration was $7.4 \%$ and required auxiliary procedure in the form of second look mini PCNL or ESWL. The overall complication rate of miniPCNL was $7.4 \%$. We did not experience any major complications such as haemorrhage necessitating transfusion/ embolization/or nephrectomy, urinary leakage, visceral injuries or sepsis as with other similar studies. ${ }^{19}$

\section{CONCLUSION}

In conclusion, mini-PCNL is a safe and more effective method for the management of renal calculi $<20 \mathrm{~mm}$ in size, upper ureteral stones, with a higher success rate and stone free rate. It is a better choice in patients with both renal and upper 
ureteric calculi due its better manoeuvrability. Mini-PCNL greatly reduces the complications of PCNL.

\section{REFERENCES}

[1] Michel MS, Trojan L, Rassweiler JJ. Complications in percutaneous nephrolithotomy. Eur Urol 2007;51(4):899-906.

[2] Valdivia JG, Scarpa RM, Duvdevani M, et al. Supine versus prone position during percutaneous nephrolithotomy: a report from the clinical research office of the endourological society percutaneous nephrolithotomy global study. J Endourol 2011;25(10):1619-25.

[3] Scoffone CM, Cracco CM, Cossu M, et al. Endoscopic combined intrarenal surgery in Galdakao-modified supine Valdivia position: a new standard for percutaneous nephrolithotomy? Eur Urol 2008;54(6):1393-403.

[4] Jackman SV, Docimo SG, Cadeddu JA, et al. The "miniperc" technique: a less invasive alternative to percutaneous nephrolithotomy. World J Urol 1998;16(6):371-4.

[5] Matlaga BR, Lingeman JE. Surgical management of stones: new technology. Adv Chronic Kidney Dis 2009;16(1):60-4.

[6] Giusti G, Piccinelli A, Maugeri O, et al. Percutaneous nephrolithotomy: tubeless or not tubeless? Urol Res 2009;37(3):153-8.

[7] Proietti S, Sortino G, Giannantoni A, et al. Singlesession supine bilateral percutaneous nephrolithotomy. Urology 2015;85(2):304-9.

[8] Armitage JN, Irving SO, Burgess NA, et al. Percutaneous nephrolithotomy in the United Kingdom: results of a prospective data registry. Eur Urol 2012;61(6):1188-93.

[9] De la Rosette J, Assimos D, Desai M, et al. The Clinical Research Office of the Endourological Society Percutaneous Nephrolithotomy Global Study: indications, complications and outcomes in 5803 patients. J Endourol 2011;25(1):11-7.
[10] Amer T, Ahmed K, Bultitude M, et al. Standard versus tubeless percutaneous nephrolithotomy: a systematic review. Urol Int 2012;88(4):373-82.

[11] Giusti G, Piccinelli A, Taverna G, et al. Miniperc? No, thank you! Eur Urol 2007;51(3):810-4, discussion 815.

[12] Mishra S, Sharma R, Garg C, et al. Prospective comparative study of miniperc and standard PNL for treatment of 1 to $2 \mathrm{~cm}$ size renal stone. BJU Int 2011;108(6):896-9, discussion 899-900.

[13] Cheng F, Yu W, Zhang X, et al. Minimally invasive tract in percutaneous nephrolithotomy for renal stones. J Endourol 2010;24(10):1579-82.

[14] Zhong $\mathrm{W}$, Zeng $\mathrm{G}, \mathrm{Wu} \mathrm{W}$, et al. Minimally invasive percutaneous nephrolithotomy with multiple mini tracts in a single session in treating staghorn calculi. Urol Res 2011;39(2):117-22.

[15] Abdelhafez MF, Amend B, Bedke J, et al. Minimally invasive percutaneous nephrolithotomy: a comparative study of the management of small and large renal stones. Urology 2013;81(2):241-5.

[16] $\mathrm{Gu} \mathrm{XJ,} \mathrm{Lu} \mathrm{JL,} \mathrm{Xu} \mathrm{Y.} \mathrm{Treatment} \mathrm{of} \mathrm{large} \mathrm{impacted}$ proximal ureteral stones: randomized comparison of minimally invasive percutaneous antegrade ureterolithotripsy versus retrograde ureterolithotripsy. World Journal of Urology 2013;31(6):1605-10. Link: https://goo.gl/2x4kEo

[17] Bozkurt IH, Yonguc T, Arslan B, et al. Minimally invasive surgical treatment for large impacted upper ureteral stones: ureteroscopic lithotripsy or percutaneous nephrolithotomy? Canadian Urological Association Journal 2015;9(3-4):E122-5. Link: https://goo.gl/z6ta7Z.

[18] Sun X, Xia S, Lu J, et al. Treatment of large impacted proximal ureteral stones: randomized comparison of percutaneous antegrade ureterolithotripsy versus retrograde ureterolithotripsy. J Endourol 2008;22(5):913-7. Link: https://goo.gl/LPBdSg.

[19] Najar FA. Safety and efficacy of mini-percutaneous nephrolithotomy in the treatment of large impacted proximal ureteral stones. J Surgical Res 2018;4(2):158. 